\title{
Calibration of test probes and experimental monitoring of changes in moisture of selected materials of subgrade structures
}

\author{
Peter Dobeš ${ }^{1, *}$, Libor Ižvolt $^{1}$, and Martin Mečár ${ }^{1}$ \\ ${ }^{1}$ University of Zilina, Faculty of Civil Engineering, Department of Railway Engineering and Track \\ Management (DRETM), Univerzitná 8215/1, 01026 Žilina, Slovakia
}

\begin{abstract}
The paper describes experimental activity carried out at the Department of Railway Engineering and Track Management of the Faculty of Civil Engineering, University of Žilina. It focuses on monitoring moisture changes in individual structural layers of the railway track body and its subgrade, performed on the railroad model, (1:1 scale). The Introduction characterizes the experimental stand models of the Department, used for monitoring the moisture changes in the structural layers. The second part of the paper focuses on the characteristics of the moisture determination method - time reflectometry (TDR method), and on the calibration of TRIME PICO IPH T3 probes for real materials of the experimental stand DRETM (crushed aggregate, fr. 0/31.5 mm protective layer, crushed aggregate, fr. $0 / 63 \mathrm{~mm}$ - embankment, clay with the addition of river gravel - foundation). The calibration was a substantial prerequisite for the subsequent humidity monitoring of the railway models. The next part of the paper presents the recorded moisture values of the structural layer materials, built in the measuring profiles of the experimental stand DRETM, measured before and during the winter period 2017/2018. The Conclusion evaluates the measured values and the determination of the input moisture values that will be used for the numerical modeling of the thermal regime of subgrade structure by the SoilVision software.
\end{abstract}

\section{Introduction}

The Department of Railway Engineering and Track Management (DRETM) of the Faculty of Civil Engineering (FCE), University of Žilina (UNIZA), has been dealing with the problem of non-traffic load on the subgrade structure since 2003. First of all, on the model of railway track in the 1:1 scale, only the thermal characteristics [1] and thermal-technical parameters of materials built in structural layers of subgrade structure were experimentally monitored and determined [2]. The application of the Canadian software SoilVision, which the DRETM started to use in 2013, required other specific parameters. These included the

\footnotetext{
* Corresponding author: dobes@,fstav.uniza.sk
} 
values of material moisture in the structural layers of subgrade structure as well as the formation foundation, and other input parameters, describing the state and properties of structural materials of subgrade structure built in railway track and its foundation. This software enables numerical modeling of the thermal regime of any railway track. At DRETM, the main focus is on the development and course of the thermal regime of the subgrade structure during the winter period. Primarily, the reason for this identification is the need of amending the legislative document [3], specifically the part of dimensioning the subgrade structure for the non-traffic load, (effects of water and frost).

For the purpose of gaining relevant input parameters for numerical modeling of thermal regime of the subgrade structure, in 2012 a new Experimental stand DRETM was built. It again represented a model of railway track structure in the 1:1 scale. This new Experimental stand DRETM first consisted of two measuring profiles, representing a railway track in the embankment. The measuring profile no. 1 represents the case when on the earthwork (railway substructure) the $450 \mathrm{~mm}$ thick protective layer (crushed aggregate, fr. $0 / 31.5 \mathrm{~mm}$ ), is placed. Its structural thickness is a result of subgrade structure dimensioning for non-traffic load of railway track in the vicinity of Žilina. The measuring profile no. 2 represents the simplest type of subgrade structure. Here, on the earthwork, built identically as in the case of the measuring profile no. 1, of crushed aggregate, fr. 0/63 $\mathrm{mm}$, the classic structure of railway superstructure (gravel superstructure) is directly placed.

As it was desirable to verify if the railway line routing affects the subgrade structure freezing, in 2016 the respective experimental stand was extended in two other measuring profiles, representing the track in a cut. (The structural layers of the formation are below the terrain level).

In the measuring profile no. 3 , a protective layer of crushed aggregate, fr. $0 / 31.5 \mathrm{~mm}$, of the same structural thickness as in the measuring profile no. 1, is placed between the ballast bed and the subgrade surface. In the measuring profile no. 4, a part of the protective layer, $300 \mathrm{~mm}$ thick, was replaced by the structural layer of Liapor (the thermal insulation material), of the structural thickness $100 \mathrm{~mm}$.

In 2017, the Experimental stand DRETM, in the embankment part, was extended in measuring profiles no. 5 and no. 6. Here, the structural composition of subgrade structure includes a thermal insulation layer of Styrodur and a cement-bound Liapor layer (Liapor concrete), to confirm the thermal insulation properties of other construction materials that could be applied in the subgrade structure. This was done not only to increase its thermal resistance - measuring profile no. 5 , but to increase its deformation resistance - measuring profile no. 6. Figure 1 shows an example of cross section of Experimental stand DRETM (measuring profile no. 1).

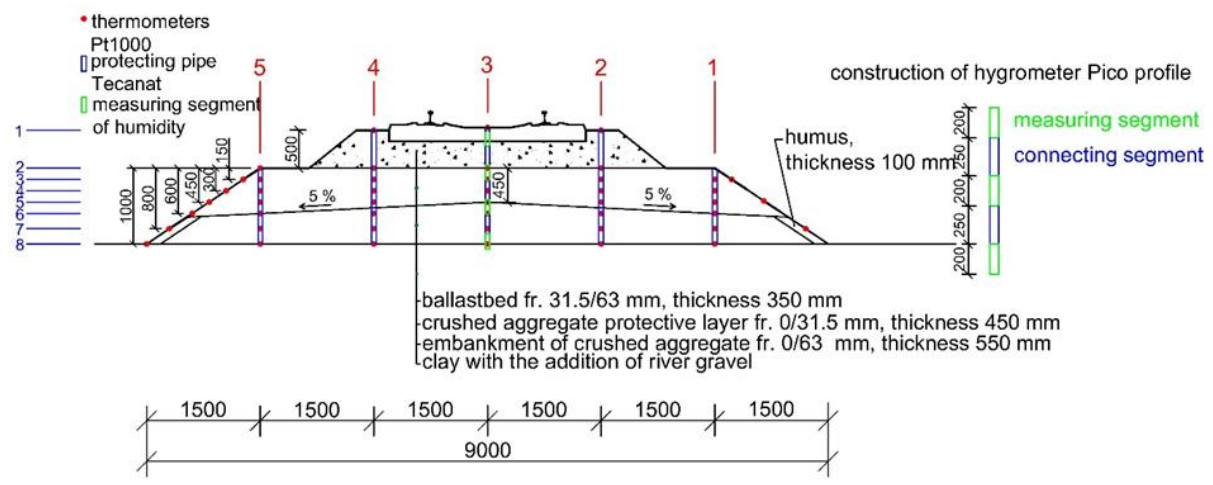

Fig. 1. Experimental stand DRETM - measuring profile no. 1 
The monitoring of the moisture regime of the subgrade structure of the Experimental stand DRETM, (particularly in the first two measuring profiles - embankment), has been carried out since 2014, using the measuring probes PICO PROFILE. As these moisture measuring probes were primarily constructed for permanent installation, which was not possible due to the number of measuring spots, in 2016 they were mechanically damaged due to frequent manipulation. Based on this experience, the probes were replaced by a more modern type of measuring probes - TRIME PICO IPH T3, that are more resistant to mechanical damaging.

The moisture measuring of subgrade structure is conducted in 6 measuring lines altogether, where 19 protecting pipes of measuring probes are embedded. Out of this number, 13 protecting pipes are placed in the embankment body of railway track (measuring profile no. 1, 2, 5 and 6), and 6 protecting pipes are located in the cut (measuring profile no. 3 and 4). The predefined calibration curves, included in the measuring probes, that were by installed by the manufacturer, are intended for fine grain materials. However, the individual measuring profiles of the Experimental stand DRETM, (structural layers of the subgrade structure), are primarily built of coarse grain materials. Due to this reason, it was necessary to carry out an own calibration of all materials built in the structural layers. The calibration methodology, as well as the calibration of the moisture probes itself, is further described in the following parts of the paper.

\section{Experimental monitoring of properties of materials built in the Experimental stand DRETM}

To determine the soil moisture or rock material moisture in general, the TRIME PICO IPH T3 probes apply the method of time reflectometry (TDR). According to this method, the moisture value is indirectly related to the dielectric constant of the non-conductive material (in our case rock material), that characterizes its ability to conduct electromagnetic waves. As the value of the dielectric constant of water is significantly higher than of solid particles (rock) and air, even slight changes in its amount cause a significant increase of the dielectric constant [6].

The long-term experience of the manufacturer, as well as our measurement experience with the previous type of TDR probes (PICO PROFILE), have shown that the dependence between the dielectric constant of rock material and the volumetric content of water in the rock is a linear one. Although the PICO PROFILE probes enabled the creation of a nonlinear calibration curve, the TRIME PICO IPH T3 probes only enable a linear calibration. The respective moisture measuring is subsequently conducted on the basis of linear calibration curves, created for tested construction materials.

\subsection{Calibration of TRIME PICO IPH T3 probes - methodology of determination of a linear calibration curve}

To protect the TRIME PICO IPH T3 probes against mechanical damage, as well as with other types of TDR probes, a protective access PVC pipe is used. The penetration of transmitted electromagnetic waves to the surrounding medium is $0.15 \mathrm{~m}$, while the highest measuring sensitivity is in the vicinity of the protecting pipe and it decreases exponentially with the distance. It is possible to achieve a higher accuracy of measured moisture values $w_{m}$ by the elliptic measurement method. Its principle lies in multiple moisture measuring at the probe rotation [6].

The creation of a linear calibration curve for various rock materials is based on the time interval $t_{p}$ determination (time recorded between the transmitted and received electromagnetic wave) for dry and saturated material. The accuracy of measured values is significantly affected by greater air gaps (bubbles), occurring in the vicinity of the protecting pipe of the probe. According to [6] it is thus more convenient to use a specimen 
with a lower humidity value $w_{m}$ instead of a dry specimen. The calibration itself, as well as the subsequent field measurement, ran smoothly and quickly, thanks to the possibility of connecting the probe to the HD2 reader. (It was not necessary to connect it to the external $\mathrm{PC})$.

\subsection{Calibration curves of experimental stand materials}

The Experimental stand DRETM is built in a part of substructure body, of three basic construction materials. The crushed aggregate, fr. $0 / 63 \mathrm{~mm}$, composes the embankment body, crushed aggregate, fr. $0 / 31.5 \mathrm{~mm}$ a protective layer of subgrade surface for embankment and cut, and the clay with the addition of river gravel that is included in the subgrade of experimental stand. Within the calibration, 6 linear calibration curves were created because for moisture monitoring two TRIME PICO IPH T3 probes, series 42857 and 43024, were available. The measured time intervals $t_{p}$, that match the respective moisture values $w_{m}$ of calibrated materials, determined by laboratory methods according to [7], are stated in Tabale 1.

Table 1. Measured time intervals $t_{p}$ of respective moisture values $w_{m}$ of construction materials.

\begin{tabular}{|c|c|c|c|c|c|c|}
\hline \multirow{2}{*}{$\begin{array}{c}\text { Material/ } \\
\text { probe } \\
\text { number }\end{array}$} & \multicolumn{2}{|c|}{$\begin{array}{c}\text { Crushed aggregate } \\
\text { fr. } 0 / 31.5 \mathrm{~mm}\end{array}$} & \multicolumn{2}{c|}{$\begin{array}{c}\text { Crushed aggregate } \\
\text { fr. } 0 / 63 \mathrm{~mm}\end{array}$} & \multicolumn{2}{c|}{$\begin{array}{c}\text { Clay with the addition of } \\
\text { river gravel }\end{array}$} \\
\cline { 2 - 7 } & $w_{m}(\%)$ & $t_{p}(\mathrm{ps})$ & $w_{m}(\%)$ & $t_{p}(\mathrm{ps})$ & $w_{m}(\%)$ & $t_{p}(\mathrm{ps})$ \\
\hline \multirow{3}{*}{42857} & 2.6 & 285 & 3.6 & 350 & 9.0 & 383 \\
\cline { 2 - 7 } & 4.8 & 370 & 5.5 & 398 & 21.8 & 647 \\
\hline \multirow{3}{*}{43024} & 2.6 & 279 & 3.6 & 345 & 9.0 & 359 \\
\cline { 2 - 7 } & 4.8 & 347 & 5.5 & 393 & 21.8 & 623 \\
\hline
\end{tabular}

The time interval $t_{p}$, matching the respective moisture $w_{m}$ of construction material, was determined by the arithmetic average of four measurements. All the values were measured at the probe's partial rotation in the protecting pipe. The calibration curves of construction materials are presented in Figure 2 and Figure 3.
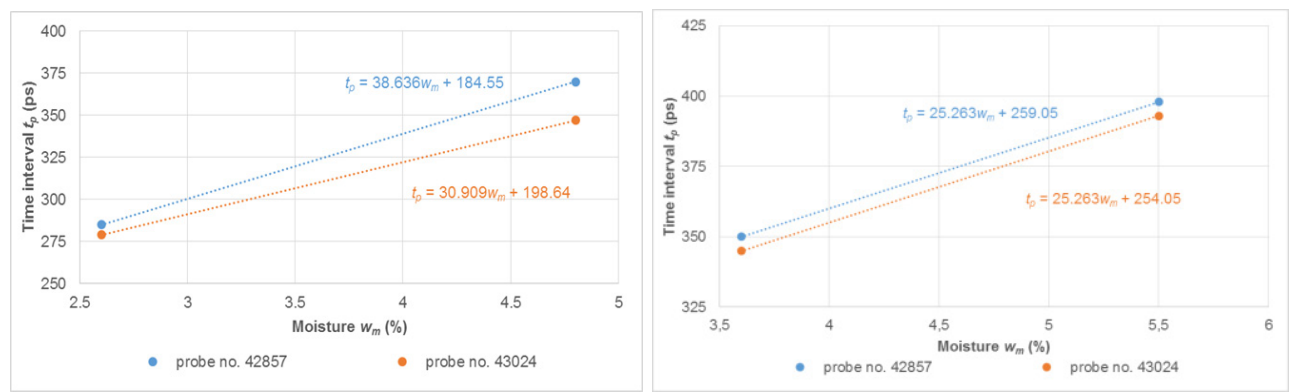

Fig. 2. Calibration curve for crushed aggregate, fr. $0 / 31.5 \mathrm{~mm}$ (on the left) and for crushed aggretate, fr. $0 / 63 \mathrm{~mm}$ (on the right) 


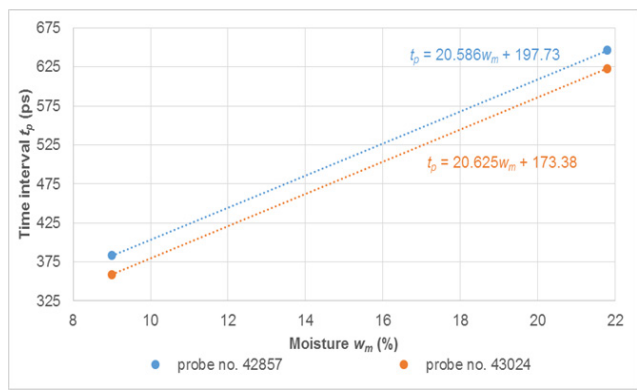

Fig. 3. Calibration curve for clay with the addition of river gravel

After creation of calibration curves, the verification of measurement accuracy of the respective probe followed. It was conducted by comparing moisture, determined by the TDR method, to the moisture determined according to norm [7], stated in Table 2.

Table 2. Comparison of moisture values determined according to the non-destructive TDR method to the values determined by the destructive method, following the procedure stated in the standard [7] for individual TDR probes.

\begin{tabular}{|l|c|c|c|c|c|c|}
\hline \multirow{2}{*}{$\begin{array}{l}\text { Material/ } \\
\text { probe } \mathrm{nr} .\end{array}$} & \multicolumn{2}{|c|}{$\begin{array}{c}\text { Crushed aggregate } \\
\text { fr. 0/31.5 mm }\end{array}$} & \multicolumn{2}{c|}{$\begin{array}{c}\text { Crushed aggregate } \\
\text { fr. 0/63 mm }\end{array}$} & \multicolumn{2}{c|}{$\begin{array}{c}\text { Clay with the addition of } \\
\text { river gravel }\end{array}$} \\
\cline { 2 - 7 } & $w_{m}(\mathrm{TDR})$ & $w_{m}[7]$ & $w_{m}$ (TDR) & $w_{m}[7]$ & $w_{m}$ (TDR) & $w_{m}[7]$ \\
\hline 42857 & $5.51-6.01$ & 5.6 & $5.03-5.46$ & 5.3 & $20.9-21.16$ & 21.2 \\
\hline 43024 & $5.79-6.09$ & 5.6 & $5.38-5.62$ & 5.3 & $21.39-21.63$ & 21.2 \\
\hline
\end{tabular}

The deviations between the destructive and non-destructive moisture measurement method move in the interval $\pm 0.5 \%$, which is also a deviation, stated by the manufacturer. However, it should be mentioned here that for better comparison it would be necessary to apply a destructive method of the moisture value determination and collect several specimens from various places. Unfortunately, this was impossible to conduct due to damage to construction).

\subsection{The measured moisture values of construction materials built in the Experimental stand DRETM before and during winter period 2017/2018}

As mentioned in the Introduction, the experimental moisture monitoring at the Experimental stand DRETM could be conducted in 19 places altogether, located in 6 various measuring profiles. Each profile is characterized by a different structural composition of subgrade structure. For the purpose of better orientation in the measured data, the paper only presents the values from 6 places. These values are the measured moisture values in the axis of each measuring profile. (They are also the most important values that in the further research will be used for numerical modelling of the thermal regime of the respective measuring profiles of the Experimental stand DRETM).

Fig. 4 depicts the measured moisture values $w_{m}$ in the axis for the measuring profile no. 1 , and the measuring profile no. 2. In the first case, the embankment body is formed by crushed aggregate, fr. $0 / 63 \mathrm{~mm}$, approx. $1000 \mathrm{~mm}$ high. In the measuring profile no. 2, in contrast to the measuring profile no. 1, a part of the embankment body, $450 \mathrm{~mm}$ thick, was replaced by a protective layer of crushed aggregate, fr. $0 / 31.5 \mathrm{~mm}$.

In the case of the measuring profile no. 1, also the moisture of the embankment foundation, which consists of clay with the addition of river gravel, was measured. It was 
not possible to measure the moisture of the ballast bed of gravel, fr. $31.5 / 63 \mathrm{~mm}, 500 \mathrm{~mm}$ thick, by the respective type of moisture probe, because of large air gaps - bubbles around the protecting pipe. Due to this reason, the moisture was determined individually, by a destructive method, according to the standard [7].
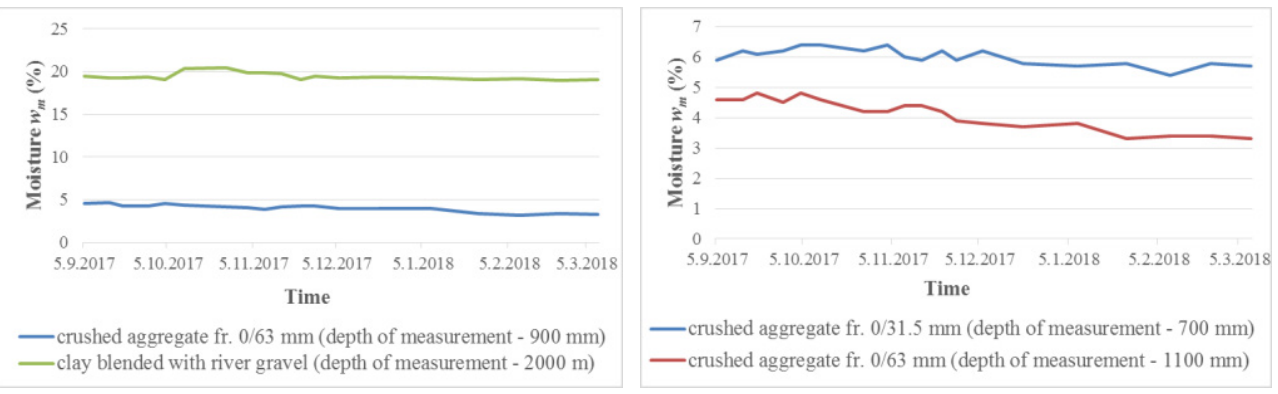

Fig. 4. Measured moisture values in the axis of the measuring profile no.1 and 2 (left - measuring profile no. 1, right - measuring profile no. 2)

Figure 5 shows the measured moisture values in the axis of the measuring profile no. 3 , that is characterized by the placement of the structural composition of the rail track model in a cut, with a protective layer of crushed aggregate, fr. $0 / 31.5 \mathrm{~mm}$ under the ballast bed, and for the measuring profile no. 4 . The profile no. 4 differs from the profile no. 3 , as its protective layer is reduced to $300 \mathrm{~mm}$, and is replaced by a thermal insulation layer of artificial aggregate Liapor, fr. $0 / 16 \mathrm{~mm}, 100 \mathrm{~mm}$ thick. The foundation (subgrade surface) of both measuring profiles is formed by clay with the addition of river gravel, whose moisture was also monitored. It was not possible to determine the moisture of the Liapor layer as it did not have a sufficient structural thickness and large air gaps occurred among the Liapor grains.
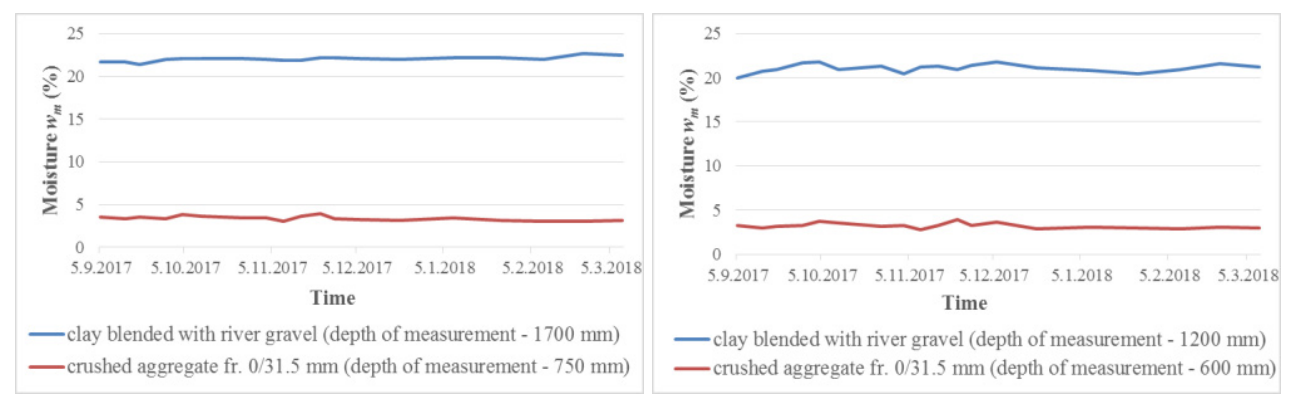

Fig. 5. Measured moisture values in the axis of the measuring profile no. 3 and 4 (left-measuring profile no. 3, right - measuring profile no. 4)

Figure 6 shows the measured moisture values in the axis of the measuring profile no. 5 - embankment. In contrast to the measuring profile no. 1 and 2, in this case the $150 \mathrm{~mm}$ thick protective layer is established in the one-sided inclination. Under this protective layer, there is a thermal insulation layer of Styrodur, $50 \mathrm{~mm}$ thick, which is placed on a $100 \mathrm{~mm}$ thick sand layer. The measuring profile no. 6 is identical to the previous measuring profile, but a layer of cement bound Liapor (Liapor concrete, $150 \mathrm{~mm}$ thick, was used as a thermal insulation layer. The foundation of both measuring profiles is also formed by clay with the addition of river gravel. It was not possible to carry our calibration for the built-in construction materials due to the insufficient structural thickness of the Styrodur layer and the inability to create a linear dependency in the case of the Liapor concrete layer. That is why the moisture monitoring was only conducted for the protective layer of crushed 
aggregate, fr. $0 / 31.5 \mathrm{~mm}$, and the foundation of clay with the addition of river gravel. In comparison to the previous measuring profiles, the beginning of the moisture measurement period in the measuring profiles no.5 and 6 is delayed (the latest structures in the Experimental stand DRETM, the expected completion immediately before winter period 2017/2018).
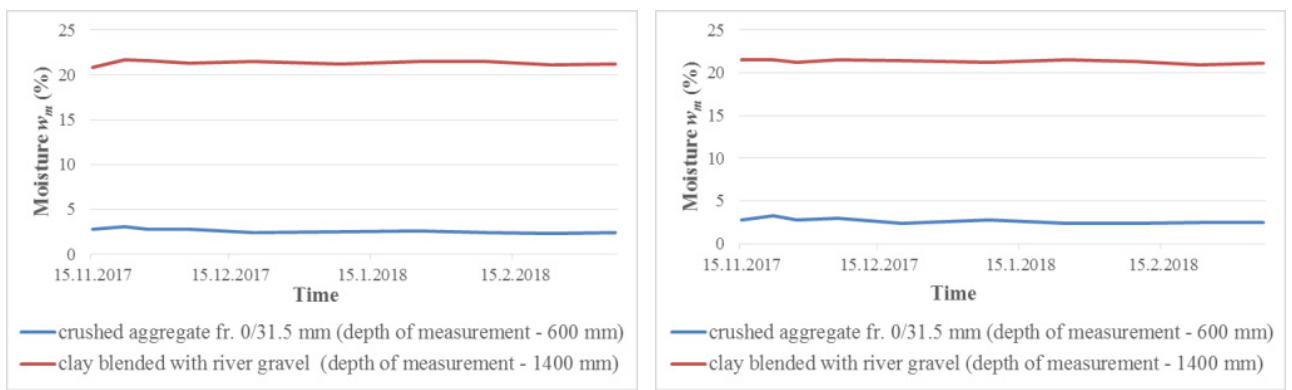

Fig. 6. Measured moisture values in the axis of the measuring profile no. 5 and 6 (left - measuring profile no. 5 , right - measuring profile no. 6 )

\section{Conclusion}

The TRIME PICO IPH T3 probes enable nondestructive measurement of soil moisture and some construction materials, applying the TDR - time reflectometry method. In contrast to the older versions of the probes (PICO PROFILE probes), these probes enable faster calibration for respective construction materials or soil, while PC connection is not necessary, (connection to the HD2 reader is sufficient). As with the previous version of measuring probes, to achieve higher moisture measurement accuracy, it is necessary to meet several conditions. These include sufficient compaction of the measured specimen, (to prevent air gaps - bubbles - in the vicinity of the protecting pipe), sufficient insertion of the probe in the soil and quality calibration for the respective tested materials.

As the TRIME PICO IPH T3 probes are primarily intended for measuring the moisture of fine grain materials, the accuracy of measured moisture values for coarse grain embankment material, (crushed aggregate, fr. 0/63 mm) was highly appreciated. If the construction material includes sufficient amount of fine grain fraction, whose presence enables its sufficient compaction and prevents larger air gaps (bubbles) in the vicinity of the protecting pipe, then such a material is suitable for moisture determination using the TDR method. As shown in Table 2 (see Part 2.2), the comparison of moisture values of respective construction materials, determined by the nondestructive TDR method and the destructive method stated in [7], confirmed the suitability of the TDR method for experimental moisture monitoring of materials built in the formation body and its foundation.

The course of the moisture changes of different measuring profiles of the Experimental stand DRETM, measured before and during winter period 2017/2018, described in 2.3, is in the given time period relatively stable, (without significant moisture fluctuation), especially for the foundation of clay with the addition of river gravel.

As already stressed in Part 2.3, the purpose of experimental moisture monitoring is the determination of characteristic moisture values of individual construction materials. These values will be subsequently used as input parameters for numerical modelling of the thermal regime of subgrade structure in the SoilVision software, specifically SV HEAT. Tab. 3 specifies the respective input moisture parameters of individual construction materials of the formation and its foundation in the Experimental stand DRETM. 
Table 3. Design moisture values of construction materials as input parameters for numerical modelling.

\begin{tabular}{|l|c|}
\hline \multicolumn{1}{|c|}{ Material } & Humidity (\%) \\
\hline Ballast bed - clean (polluted) & $1.0^{*}(2.0-5.0)^{*}$ \\
\hline Crushed aggregate & $4.0(5.0-6.0)^{* *}$ \\
\hline Clay & 20.0 \\
\hline
\end{tabular}

Note: * determined by the destructive method according to [7], the moisture value depends on the level of pollution,

** value valid for crushed aggregate with higher content of fine grain fraction.

The presented results are the partial results of solving the VEGA grant project 1/0275/16 "Structure optimization of sleeper subgrade due to non-traffic load aspect".

\section{References}

1. L. Ižvolt, P. Dobeš, M. Mečár, Procedia Engineering, 161, 1057-1063 (2016)

2. L.Ižvolt, P. Dobeš, A. Pultznerová, Procedia Engineering, 161, 1049-1056 (2016)

3. TNŽ 73 6312, The design of structural layers of subgrade structures [Návrh konštrukčných vrstiev podvalového podložia]. (GR ŽSR. Slovakia, 2005)

4. L. Ižvolt, P. Dobeš, M. Pitoňák, Some experience and preliminary conclusions from the experimental monitoring of the temperature regime of subgrade structure. In: Computer in railways XIV: Railway engineering design and optimization. [S.1.]: WITpress, 2014. ISBN 978-1-84564-766-7. pp. 267-278. (WIT transactions on the built environment, Vol. 135. ISSN 1746-4498), (2014)

5. Ižvolt, L., Dobeš, P.: Test procedure impact for the values of specific heat capacity and thermal conductivity coefficient. In: Procedia Engineering: XXIII R-S-P seminar: Theoretical foundation of civil engineering. ISSN 1877-7058. Vol. 91, s. 453-458, (2014)

6. Trime Pico-profile manual.

7. STN 721012 Laboratory determination of soil moisture, 09/1980. 